\title{
Research on College Students' Physical Education Motivation in Computer Network Environment
}

\author{
Yan Gong ${ }^{1}$ \\ ${ }^{1}$ Jiangxi Science and Technology Normal University, Nanchang, Jiangxi, China, 330003
}

Keywords: Computer Network Environment, College Students, Physical Education Motivation

\begin{abstract}
With the popularity of computer networks, more and more college students addicted to the Internet, while ignoring the physical education and exercise. According to this kind of situation, it is necessary to combine the functions and advantages of the computer network to stimulate the interest of college students in sports learning. The necessary methods and ways are: the physical education teachers and management of the school should attach great importance and strengthen the goal and the awareness degree of the school physical education; strengthen the campus culture in the construction of physical education curriculum publicity; provide facilitate and method guidance for college students extracurricular sports activities; encourage civil society organizations and institutions provide help and create the conditions of sports learning for the physical education.
\end{abstract}

\section{Introduction}

According to the relevant institutions of higher education in the country, the purpose and purpose of physical education in the new era university is to let the students have a healthy body. Methods to improve the quality of college students are: the use of learning motivation, learning attitude, learning interest. It is mainly embodied in the weak structure of college students 'physical education curriculum. It is only necessary to teach college students' general sports knowledge and skills, but not enough attention to college students need to expand their personal emotion and morality through sports activities. This paper aims to stimulate the motivations of college students 'physical education through the use of modern teaching methods. The application of computer network teaching provides a new foundation and opportunity for college students' physical education teaching. Taking the health of college students as the center, the college students use the computer network to select their own of the physical exercise, so as to improve their physical fitness.

\section{Analysis of the Factors Affecting the College Students' Learning Motivation from the perspective of Sports Psychology}

Values and Expectations Cognition. The cognition of values and expectations is the main driving force for college students to carry out various activities. When college students find that they can get value in physical education will consciously take the initiative to complete the sports goals and behavior. The core of the theory of expectation is the reward of rewarding the behavior of college students in sports. Sportsists generally have the following conclusions about the meaning of this "value": the three types of positive energy values (intrinsic value, extrinsic value, real value) and a class of negative energy values (costs or pay).

The Attribution Theory of Motivation. Weiner divides the causes of success and failure from the perspective of cognitive psychology into three dimensions, including internal and external attribution dimension, stable attribution dimension, and control attribution dimension. Weiner believes that the four elements of attribution motive are effort, ability, luck and task difficulty, its manifestations are: the results of sports and results attributable to the success; ability to succeed, learning, efforts to increase attribution Learning interest, and learning ability; some non-stable attribution will reduce the ability to learn.

The Concept of Self-Efficacy Analysis. Self-efficacy refers to the ability of an individual to determine whether he is capable of performing an action. Self-efficacy of college students in the 
physical education will be selected in the technical content of sports competitions, although in the face of learning difficulties will be some negative emotions, but can face the difficulties, and through the individual learning to complete the degree of desire Learning objectives, so as to promote the students self-efficacy was greatly improved. Self-efficacy of college students in the face of learning difficulties and lack of capacity, the less retreat, but the learning task is completed and fully believe that they can overcome the difficulties faced.

\section{The Current Situation Faced by College Students in Learning Sports}

College Students Are Not Demanding on Their Own Physical Education Goals. The intensity of physical education motivation is based on the expectations of college students on their own learning goals to determine the level. College students on their own sports ability expectations are not high, that the physical education to pay less after the return, so that there is no value in physical exercise. At the same time, feeling physical exercise and learning very tired, very bitter, little effect. College students' motivation to learn sports is very weak, requiring contemporary college students to cultivate the ability to learn books on the one hand, on the other hand to cultivate a healthy body, the two are indispensable, which is a qualified or excellent contemporary College students put forward higher demands.

The Stability and Non-Stability of College Students in Physical Education. The reasons for the stability of physical education attribution are: the level of learning effort, learning attitude, learning methods, physical fitness; physical education attribution of non-stable factors are: physical education environment, curriculum or task difficulty, sports test Luck, sports teacher's ability. It is worth emphasizing that the definition of physical education is not good attributable to non-stable attribution, is a negative and one-sided.

College Students Are Lacking of Learning Self-Efficacy. For college students who wish to learn for sports, they will set their own advanced learning plans. They will not stop the pace of progress when they encounter difficulties and difficulties. They will continue to try their own to improve their sports skills and skills. Give yourself the plan and get the results of sports learning. Some students with a sense of efficiency at the end of the school have a feeling of learning and want to give up and escape, not to practice and try, such a result must be low physical education ability. The physical education teachers in the teaching to take restrictive teaching, college students will be greatly reduced the motivation of physical education, so that students have negative emotions and learning anxiety syndrome. Students think they do not have the ability to learn sports.

\section{How to Stimulate Physical Education Motivation in the Computer Internet Environment}

Provide a Wealth of Sports Programs to Enhance the Students' Interest in Learning and Exercise Will. There are tens of thousands of sports learning resources on the Internet. Sports teachers can arrange different types of sports activities and projects to improve the level of college students' physical education. For example, the contents of related sports learning in the network can be classified as Sports origin, evolution process, sports stars and popular sports activities. But also the world's more well-known event events broadcast video copy of the information, familiar athletes race conditions, professional sports teaching video to explain, sports celebrity book and event history and college students to share and learn, and better for the teaching content to do Vivid supplements.

Help College Students to Reduce the Objective and Passive of Sports Learning. College students can study through the Internet after the school want to learn or interested in sports activities to learn. To find the sports learning resources, there are difficult physical movements can ask the teacher or with the students to complete the learning task. Conditional circumstances, according to the action in the video slow down or repeat their movements to master the skills of sports learning. College students can use their own free time through the Internet to carry out physical education courses, but also through the network and school teachers to communicate and exchange. In the exchange of mutual education not only enhance the teacher-student friendship, and physical 
education teachers can also be based on the individual's ability and quality of teaching students, will produce both satisfied with the academic performance. Internet learning without geographical, environment-limited barriers for the development of sports in front of fair and impartial provides the basis for realization.

Pave the Way for College Students to Learn and Improve the Motivation of College Students to Learn. In addition to formal college physical education courses, but also with different sports folk sports associations and exchanges. Folk society in the mountain, cycling, walking, dancing, boxing and other members of the activities will be on the Internet to convene and publish event information, share the activities of the video and photos, experience sharing, etc., so that a variety of professional, More opportunities to participate in social activities and practice, resulting in unity and fraternity atmosphere, and jointly promote the Chinese sports faster and better and better development, so that physical exercise has become one of the ways of healthy life of college students.

\section{Conclusion}

In the teaching of physical education, teachers should take stimulating students' learning motivation as a primary task. First of all, cultivating good learning motivation can effectively improve the quality of teaching and the physical quality of college students, and secondly, provide the basis and guarantee for college students to adhere to physical exercise after going to society. College students' motivation to learn sports can be achieved by professional education, stimulate potential, teaching methods adjust and other methods. In the teaching of the choice and arrangement, teachers should fully cultivate and stimulate college students to learn the motivation of sports to get a good teaching effect. To realize the significance and value of physical education, we should construct an effective physical education teaching system. We should study the various channels and links of physical education from various angles and levels, so that we can study the physical education of college students. A scientific system of physical education should be integrated into the community and daily life, practical and suitable for the development of physical and mental development of college students in order to allow all ages and all levels of college students have their own personalized physical education teaching program. Only the teaching subjects of the structure and teaching activities can be combined, physical education can make college students become a strong physique of the successor of communism.

\section{References}

[1] Xu Yingwen, Xiao Zhenhuai. Study on Motivating College Students' Motivation of Physical Education in Computer Network Environment [J]. Journal of Jilin Province Education College (End), 2014, (09): 17-18.

[2] Guo Xiaowen. Study on the Autonomous Learning of Physical Education Majors Based on Network Environment [D]. Fujian Normal University, 2015, 16(3): 62-67.

[3] Hong Xiao Xiao. Internet age college students' sports lifestyle survey of the status quo[D]. Shandong University, 2014

[4] Xu Yingwen, Xiao Zhenhuai. Computer network environment to stimulate college students in sports learning motivation[J]. Journal of Jilin Province Education College (middle), 2014, (09): $17-18$. 